\title{
What makes age diverse teams effective? Results from a six-year research program ${ }^{1}$
}

\author{
Wegge, J. ${ }^{\text {** }}$, Jungmann, F. ${ }^{\mathrm{a}}$, Liebermann, S. ${ }^{\mathrm{a}}$, Shemla, M. ${ }^{\mathrm{a}}$, Ries, B.C. ${ }^{\mathrm{b}}$, Diestel, S. ${ }^{\mathrm{b}}$ and Schmidt, K.-H. ${ }^{\mathrm{b}}$ \\ ${ }^{\mathrm{a}}$ Work and Organizational Psychology, Technische Universität Dresden, Zellescher Weg 17, 01069 Dresden, \\ Germany \\ ${ }^{\mathrm{b}}$ Leibniz Research Centre for Working Environment and Human Factors, Technische Universität Dortmund, \\ Ardeystraße 67, 44139 Dortmund, Germany
}

\begin{abstract}
Based on a new model of productivity in age diverse tams, findings from a six-year research program are reported in which data from more than 745 natural teams with 8,848 employees in three different fields (car production, administrative work, financial services) were collected. Moreover, central assumptions of this model were tested with a representative survey of the German workforce $(\mathrm{N}=2,000)$. Results support both significant advantages and disadvantages for age-mixed teams. Based on the findings, the following preconditions for the effectiveness of age diverse teams are identified: high task complexity, low salience and high appreciation of age diversity, a positive team climate, low age-discrimination, ergonomic design of work places, and the use of age differentiated leadership. Based on these insights, we developed a new training for supervisors, which addresses the aforementioned aspects and seeks to improve team performance and health of team members. It was found that the training reduces age stereotypes, team conflicts and enhances innovation. Thus, we can conclude that effective interventions for a successful integration of elderly employees in work groups are available and that combinations of measures that address ergonomic design issues, team composition and leadership are to be strongly recommended for practice.
\end{abstract}

Keywords: age-diversity, team performance, health, age salience, appreciation of age diversity

\section{Introduction}

Due to the demographic change in Germany and most other European countries, the proportion of elderly workers is increasing. It is expected that in the future organizations will experience difficulties in finding young workers and will have to rely more heavily on older (50plus) workers. Therefore, human resource management is called upon to find strategies for the successful integration of older employees. In this article, the possibility of using age-mixed teams as a potential strategy is discussed, updating also what is known about the effects of age diversity.

Based on theories of social categorization processes [22] and models of information processing [24], age diversity in teams may result in advantages (e.g., utilization of differences in experience for problem solving) as well as disadvantages for team- work (e.g., intensification of emotional conflicts in groups). Recent review articles [30] and metaanalytic studies [12] have shown, however, that negative effects of age diversity in teams are more likely than positive effects. Thus, more research is needed to identify the conditions favorable for utilizing age diverse teamwork.

In line with this idea, a new model (Figure 1), which describes different paths linking team composition in terms of age with group effectivity, was developed. This model explains why prior diversity research has often found contradicting effects for the impact of age diversity on team performance and other outcomes (e.g., satisfaction, health). In the following, the theoretical foundation of this model is outlined. Next the empirical basis of the project is summarized and the key findings are presented.

\footnotetext{
${ }^{1}$ This research was supported by six grants from the German research foundation (DFG, WE 1504/8-1/2/3 and SCHM 851-1/2/3).

* Corresponding author is Prof. Dr. Jürgen Wegge, tel. no: +49 351463-33784 (-33589 fax), E-mail: wegge@psychologie.tu-dresden.de
} 


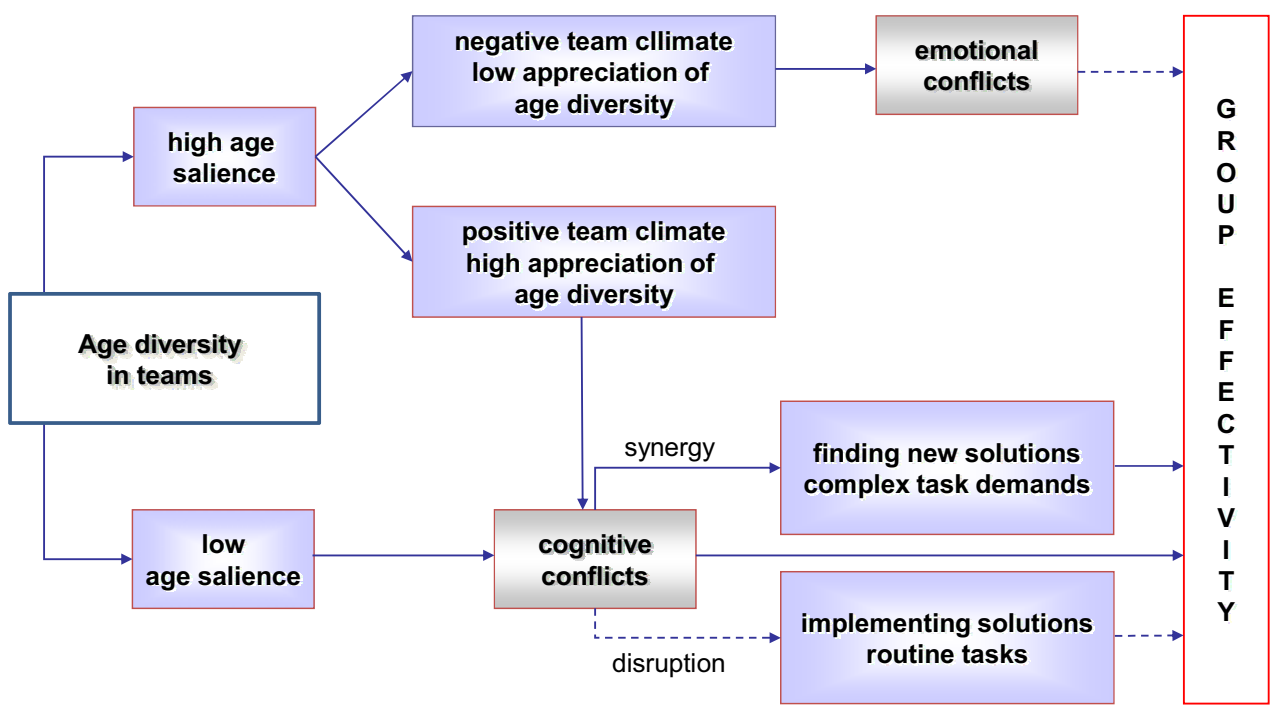

Fig. 1: A new model of group effectivity in age-diverse teams

\section{Theoretical background}

Diversity research has mainly been guided by two psychological traditions: the social categorization perspective $[9,22]$ and the information processing perspective [33]. The starting point for the social categorization theory is the idea that individuals are assumed to have a desire to maintain a high level of self-esteem. This is often achieved through a process of social comparison with others. In making these comparisons, individuals first define themselves through a process of self-categorization in which they classify themselves and others into social categories using salient characteristics that are relevant in a specific context. Similarities and differences between team members form the basis for categorizing oneself and others into groups, distinguishing between similar in-group members and dissimilar out-group members. As people tend to favor in-group members over out-group members, trust in-group members more, and are more willing to cooperate with in-group members [25] diversity may thus lead to cognitive biases, discrimination, and emotional conflict in teams. The second perspective is much more optimistic. Based on cognitive theories of information processing, it is assumed that more diverse groups hold a broader range of task-relevant knowledge, skills, and abilities. Furthermore, they are more likely to consist of members with different experiences, opinions, and viewpoints. Accordingly, diversity may improve team functioning through an increased range of knowledge and expertise. Specifically, the use of different knowledge sources might facilitate taskrelevant elaboration [24] and lead to task-related conflicts (cf. [11]), which may consequently result in more mature decisions and improved performance. This positive impact of diversity can be expected especially when tasks benefit from multiple perspectives and diverse knowledge [3]. Thus, diversity may enhance group functioning in tasks that require innovation and complex decision-making.

Wegge [27] and van Knippenberg et al. [24] have suggested that these theoretical formulations are not conflicting but address different aspects of the psychological processes by which diversity may influence work unit outcomes. In other words, it is sug- 
gested that the effects of team diversity can be explained and described by both theories, and that work unit diversity may exert either or both positive and negative effects simultaneously. The model in Figure 1 therefore integrates both perspectives and indicates the main moderating and mediating variables regarding potential benefits and risks related to age diversity $[19,31]$. The authors propose that - ceteris paribus - age diversity in work groups will have negative effects on group performance, motivation and health of group members because objective age diversity in teams increases the salience of age diversity (i.e. whether diversity is indeed observed by group members). When the salience of age diversity is high, team conflict increases and this yields low team effectiveness. However, it is further postulated that, under favorable conditions, beneficial effects should be observed, too. High appreciation of age diversity (i.e. positive judgments regarding the value of age diversity in team work), a positive team climate and high team task complexity (novelty) are considered as favorable moderating variables. Thus, in testing the model, corresponding measures of age diversity salience, age diversity appreciation and team climate were developed. Moreover, we examined the mediating influence of conflicts and differentiated between age diversity in groups that engage in complex or more routine team tasks.

\section{Empirical basis of the research project}

Five independent studies were conducted to examine the validity of the research model. Due to restrictions in data collection in some fields, it was not always possible to assess the complete set of variables. In the following, an overview of the specific research designs and measures is given. All measures used in these studies were sufficiently reliable (see single publications for detailed information).

\subsection{Types of teams and research designs}

Three different types of teams were analyzed in this project: (i) Administrative teams working in taxoffices (222 teams in an archival study, $\mathrm{n}=4,538$; 155 of those teams were also observed longitudinally over 2 years, $\mathrm{t} 1=155$ teams with $\mathrm{n}=722, \mathrm{t} 2=69$ teams with $n=397)$ and pension-offices (67 teams with $\mathrm{n}=435$ in a longitudinal study over 2 years), (ii) 245 financial service teams $(n=2514$ over a period of four years, only demographic and performance data were available), and (iii) 56 car production teams $(n=639$, demographic data and data on absenteeism and performance over one year were available). In addition, in order to test the generalizability of the core assumption of our model (i.e. the link between age diversity, age diversity salience, age discrimination and health disorders), we also conducted a representative survey of the German workforce $(\mathrm{N}=2,000)[28]$.

\subsection{Measures}

- Age diversity was calculated using either the standard deviation of objective age within the team [8] or the Blau-index (see [6]). In the representative survey of the German workforce age diversity was assessed with a single question regarding the age distribution within the participants` own work team.

- Age-diversity salience was measured with a newly developed questionnaire comprising six items (e.g., "The age difference between my colleagues is very conscious to me"; "The different age of the members in our group is a topic which is discussed") [20].

- Appreciation of age diversity was assessed with six newly developed items (e.g., "My group benefits from input from younger as well as older members" and "A group works better if it consists of members from different age groups") [32].

- Team climate was measured with nine items presented by Moltzen and van Dick [14]. A sample item is "We support each other in our group, so we can do our work as good as possible ".

- Emotional and task conflicts in teams were assessed with scales presented by Jehn [11]. Sample items are "It is obvious that there are personal conflicts in our group" and "Conflicts concerning tasks occur in our group frequently".

- Task complexity was controlled for in one large study (archival tax office study, $\mathrm{n}=$ 4,500) where employees had the same job levels and basic task requirements but either worked on routine or complex tax declarations [29].

-Age discrimination was measured in the representative survey of the German workforce with eight items [28] based on the Nordic Age Discrimination Scale [7]. Participants 
indicated the degree of age discrimination in their workplace with regard to promotion, training, development, appraisals, wage increases and change processes. A sample item is "Older workers have less opportunities for training at work".

- Ergonomic workload was measured in the automotive study with the "Automotive Assembly Worksheet" [6].

- Several dependent variables were assessed in the studies:

* Performance was measured with objective processing times in tax offices, with objective goal attainment scores regarding annual commission targets of consultants, or with the number of assembly errors in automotive production.

* Team identification was assessed with five items drawn from Haslam [9]. A sample item is "When I talk about our group, I usually say "we"“.

* Job satisfaction was measured with seven items drawn from Neuberger and Allerbeck [15], e.g. "How satisfied are you with work as a whole?".

* Health was measured with questionnaire items related to a list of 13 specific health disorders (e.g. pain in arms and hands, fatigue of legs, weariness, inner tension) [34], five items assessing emotional exhaustion (e.g. "I feel emotionally drained by my work") [5] and data on absenteeism in automotive production. In the representative survey four items were used to assess subjective health and self-reported absenteeism due to sickness.

* Innovation was measured with seven items from Janssen (e.g. "Our group creates new ideas concerning solutions for difficult problems") [10]. In two studies, data on conflicts and innovation were also collected from team supervisors.

In the following, we summarize the seven key conclusions of this research project by illustrating the main findings and by referring to individual articles that describe the corresponding results in more detail.

\section{Recommendations for utilizing age diverse team work in organizations}

\subsection{Offer complex tasks without time pressure}

The influence of age composition on group performance and health disorders was examined using data from 4,538 federal tax employees working in 222 natural work teams [29]. As hypothesized, age diversity correlated positively (resp. negatively) with performance in groups solving complex (resp. routine) decision making tasks. This finding was replicated when analyzing performance data collected one year later. Age diversity was also positively correlated with health disorders, but only in groups working on routine decision-making tasks. The findings provide support for information processing models positing that diversity can have positive effects on performance outcomes when tasks require complex decision-making. In our view, this pattern of results is also consistent with other models (e.g., the theory of Baltes [2] and the taxonomic approach of Warr [26]) that propose that age-related deficits may be reduced by high task variety and be compensated for through selection, optimization and compensation strategies under conditions of complex task requirements without much time pressure.

In support of this general idea, we also found a significant correlation $(\mathrm{r}=.13)$ between age diversity in financial consultant teams and average team performance [21]. This effect was hypothesized because selling a large number of different financial products to private and small enterprise customers requires complex and creative decision making. Interestingly, further analyses revealed that the benefits of team resources associated with increased age could be explained by organizational tenure (i.e. experience). The results further suggest that the performance enhancing effect of tenure diversity was stronger the more women worked in a team.

\subsection{Reduce age diversity salience in teams and related conflicts}

In two studies $[16,28]$ it was found that age differences in teams are positively correlated with age diversity salience ( $r=.55$ in [16] and $r=.24$ in [28]). In addition, the findings show that the negative relationship between age diversity salience and innovation (rated by employees) as well as burnout was fully mediated by conflicts within groups [16], and that high age diversity salience was positively corre- 
lated with age discrimination $(\mathrm{r}=.14)$ and the activation of stereotypes against older workers $(r=.20)$ [28]. The significant correlation between objective age diversity, age diversity salience and conflicts strongly supports the social categorization perspective. Thus, in order to enhance the effectiveness of age diverse teams it is recommended to act towards the reduction of age diversity salience (e.g. by establishing a balanced age distribution or by leadership training, cf. below).

\subsection{Promote high appreciation of age diversity}

Ries et al. [17] investigated the moderating effect of appreciation of age diversity in a subsample of 140 tax-office teams. It was expected that the negative associations between age salience and group effectiveness should be more (less) pronounced in groups where group members have a low (high) level of appreciation of age heterogeneity. In addition, it was hypothesized that team conflicts mediate this moderating effect. In support of this idea, results from a moderated mediation regression analysis indicate that the moderating effect of appreciation of age diversity is based on different levels of conflicts within groups. In the same vein, Wegge et al. [32] found in a cross lagged panel design with 69 teams from pensionoffices that high appreciation of age diversity yields higher job satisfaction, lower conflicts, and higher innovation.

\subsection{Promote a positive team climate}

The expected moderating effect of team climate on the relationship between age diversity and team efficiency was tested in a field study including 66 work teams from the administrative sector [17]. Results confirm the expected moderating effect. In particular, whereas in teams with a positive team climate, an increase in age heterogeneity leads to increments in innovative performance, in teams with a negative team climate, age heterogeneity contributes to a decrease of innovative performance. Moreover, based on a multilevel design, we also found team climate to exert moderating effects on the cross-level relationship between age diversity as a group characteristic and burnout as an individual health outcome. In case of a good team climate, increasing age diversity results in a decrease of burnout, whereas age diversity is positively related to burnout when team members report a bad team climate. In summary, a good team climate has been revealed as a crucial component of high age diverse teams amplifying beneficial effects of age diversity on performance and health. Thus, in managing age diversity, team leaders should enhance team climate by giving clear definitions of objectives and visions, supporting innovation and focusing on refinement of team outcomes [1].

\subsection{Reduce age-discrimination (ageism) at work}

The representative survey of the German workforce $(\mathrm{N}=2,000)$ [28] also examined potential interactions between the salience of age diversity in teams and the strength of age discrimination (ageism) experienced at the workplace. It was found that the association between age diversity salience and health of employees was moderated by age discrimination. When employees perceived high age-discrimination at work, the salience of age diversity in teams had a significant negative impact on health $(\beta=-.14)$. This effect was not observable in employees with low levels of age discrimination $(\beta=.06$, n.s.) Thus, the detrimental effects of age diversity salience seem to be most prominent under conditions of high age discrimination.

Interestingly, a closer inspection of this data shows that these links also vary for different age-groups [13]. Following the arguments of the social identity theory, the negative influence of age diversity on an individual's health depends on the extent to which one identifies with the age-subgroups in the team. Employees that are positioned in the middle of the age-continuum should be able to identify with both younger and older employees. In contrast, team members positioned at the extreme ends will have difficulties identifying with the group at the other end. Additionally, for those at both extreme ends of the continuum, age is a more noticeable characteristic than for those positioned at the middle. Thus, it can be concluded that both younger and older employees will be more affected by working in age-diverse teams than middle-aged employees. Indeed, separate regression analyses for three age-groups indicated that while age diversity had negative impact on the health of young and old employees, there was no relationship between age diversity and health for middle-aged employees.

\subsection{Improve ergonomic design for teamwork}

Prior research suggests that appropriate team composition regarding age and ergonomics workplace design may reduce the decline of productivity in ag- 
ing employees working at paced assembly lines. Fritzsche et al. [6] investigated the simultaneous effects of both team level factors on individual absenteeism (time lost and frequency) and team performance $(22,821$ errors) over one year in a sample of 56 natural car-manufacturing teams $(\mathrm{N}=623)$. Results show that age was positively associated with absenteeism and mistakes in work planning. In contrast, controlling for physical workload, it was found that age diverse teams were more effective than age homogenous teams, but only if diversity was measured as a balanced mix across age categories (Blauindex) rather than as separation of old and young (standard deviation, SD). Hierarchical linear modeling (HLM) analyses further demonstrated that productivity was most strongly affected by workplace ergonomics because high physical workload amplified age-related increases in absenteeism and was associated with more assembly errors. Once again, it was also found that gender diversity had a performance enhancing effect. Considered together, these results indicate that both team diversity and ergonomic workplace design may reduce age-related productivity risks in manufacturing by maintaining the work ability of older employees and improving production quality.

\subsection{Promote age-differentiated leadership of supervisors}

Based on these findings, a modular training for supervisors was developed to address these recommendations and to improve team performance. In the first training module, information about age related changes in performance and work motivation were presented to supervisors. Additionally, the development and consequences of age stereotypes as well as appreciation of age differences were explained and discussed. Building on this theoretical background, the supervisors deepened these topics in the second training module by discussing strategies and drawing practical implications for their everyday work life. The training was conducted with 32 supervisors (209 employees) working in a tax office [18]. The evaluation design consisted of training and waiting control groups. Data were collected before and four months after training. An additional follow up measure was conducted 12 months after the training. It was found that the training reduces age stereotypes, team conflicts, and enhances innovation.

\section{Conclusions and future research}

The main goal of this project was to analyze the influence of age diversity on team effectivity, including satisfaction, innovation and health of employees. Mediating and moderating variables like attitudes towards age diversity in teams and task complexity were also part of the analyses. Based on the consistent findings we can conclude that effective interventions for the successful integration of elderly employees in work groups are available and that combinations of measures that address ergonomic design issues, team composition and leadership processes in teams are to be strongly recommended.

Future research should attempt covering the complexity of diversity in teams more appropriately by including more than one diversity attribute at the same time (e.g., [6,21]) and by analyzing also the alignment of multiple characteristics between team members based on the faultline approach (hypothetical dividing lines that may split a group into subgroups; see [23]). Using existing data from $232 \mathrm{em}-$ ployees working in 58 natural tax office groups with four team members each, Breu, Wegge and Schmidt [4] calculated faultlines regarding age, sex and tenure of team members. The results support the assumption that stronger faultlines lead to more cognitive conflicts in teams and also to more burnout. Importantly, these results were found when controlling for traditional diversity indicators. Hence, it can be concluded that the faultline concept is indeed fruitful and extends traditional research on team composition.

\section{References}

[1] N.R. Anderson and M.A. West, Measuring climate for work group innovation: development and validation of the team climate inventory, Journal of Organizational Behavior 19 (1998), 235-258.

[2] P.B. Baltes, On the incomplete architecture of human ontogeny. Selection, optimization, and compensation as foundation, American Psychologist 52 (1997), 366-380.

[3] C.A. Bowers, J.A. Pharmer, and E. Salas, When member homogeneity is needed in work teams - A meta-analysis, Small Group Research 31 (2000), 305-327.

[4] C. Breu, J. Wegge, and K.-H. Schmidt, Alters-, Geschlechtsund "Tenure"-diversität in Verwaltungsteams - Erklären Faultlines mehr Varianz bei Teamkonflikten und Burnout als traditionelle Diversitätsindikatoren? [Age-, gender- and tenurediversity in administrative teams: Do faultlines explain more variance in team conflicts and burnout compared to traditional diversity indicators?], Zeitschrift für Arbeitswissenschaft 64 (2010), 174-159.

[5] A. Büssing and K.-M. Perrar, Die Messung von Burnout. Untersuchung einer deutschen Fassung des Maslach Burnout Inventory (MBI-D) [Measuring burnout: A study of a German 
version of the Maslach Burnout Inventory (MBI-D)], Diagnostica 38 (1992), 328-353.

[6] L. Fritzsche, J. Wegge, M. Schmauder, M. Kliegel, and K.-H. Schmidt, Team diversity, workplace ergonomics and agerelated declines in health and performance of car manufacturing teams (submitted).

[7] T. Furunes and R.J. Mykletun, Age discrimination in the workplace: Validation of the Nordic Age Discrimination Scale, Scandinavian Journal of Psychology 51 (2010), 23-30.

[8] D.A. Harrison and K.J. Klein, What's the difference? Diversity constructs as separation, variety, and disparity in organizations, Academy of Management Review 32 (2007), 1199. 1228

[9] S.A. Haslam, Psychology in organizations: The social identity approach ( $2^{\text {nd }}$ ed.), Sage, London, 2004.

[10] O. Janssen, Job demands, perceptions of effort-reward fairness and innovative work behavior, Journal of Occupational and Organizational Psychology 73 (2000), 287-302.

[11]K.A. Jehn, A multimethod examination of the benefits and detriments of intragroup conflict, Administrative Science Quarterly 40 (1995), 256-282.

[12] A. Joshi and H. Roh, The role of context in work team diversity research: A meta-analytic review, Academy of Management Journal 52 (2009), 599-627.

[13] S. Liebermann, J. Wegge, F. Jungmann, and K.-H. Schmidt, Age diversity as a health hazard for specific age groups (submitted).

[14]K. Moltzen and R. van Dick, Arbeitsrelevante Einstellungen bei Call Center-Agenten: Ein Vergleich unterschiedlicher Call Center-Typen [Work-relevant attitudes among call center agents: Comparison of different call center types], Zeitschrift für Personalpsychologie 1 (2002), 161-170.

[15] O. Neuberger and M. Allerbeck, Messung und Analyse von Arbeitszufriedenheit [Measurement and analysis of job satisfaction], Huber, Bern, 1978.

[16] B.C. Ries, S. Diestel, J. Wegge, and K.-H. Schmidt, Die Rolle von Alterssalienz und Konflikten in Teams als Mediatoren der Beziehung zwischen Altersheterogenität und Gruppeneffektivität [The role of age salience and conflicts in teams as mediators on the relationship between age heterogeneity and group effectivity], Zeitschrift für Arbeits- und Organisationspsychologie 54 (2010), 117-130.

[17]B.C. Ries, S. Diestel, J. Wegge, and K.-H. Schmidt, Altersheterogenität und Gruppeneffektivität - Die moderierende Rolle des Teamklimas [Age diversity and group effectiveness - The moderating role of team climate], Zeitschrift für Arbeitswissenschaft 64 (2010), 137-146.

[18]B.C. Ries, S. Diestel, J. Wegge, and K.-H. Schmidt, Konzeption, Durchführung und Evaluation eines Trainings zu ,Altersheterogenität im Team als Ressource erkennen und nutzen' [Conceptualizing, conducting and evaluating a training on 'identifiying and using age heterogeneity in teams'], in: Mensch, Technik, Organisation - Vernetzung im Produktionsund Herstellungsprozess, GfA, eds., GfA Press, Dortmund, 2011, pp. 93-96.

[19]C. Roth, J. Wegge, and K.-H. Schmidt, Konsequenzen des demografischen Wandels für das Management von Humanressourcen [Consequences of demographic changes for the management of human resources], Zeitschrift für Personalpsychologie 6 (2007), 99-116.

[20]K.-H. Schmidt and J. Wegge, Altersheterogenität in Arbeitsgruppen als Determinante von Gruppenleistung und Gesund- heit [Age heterogeneity in workteams as determinant of group effectivity and health], in: A. Dehmel, H.H. Kremer, N. Schaper, and P.F.E. Sloane, eds., Bildungsperspektiven in alternden Gesellschaften, Lang, Frankfurt, 2009, pp. 169-183.

[21]M. Shemla, M. Thies, J. Wegge, and K.-H. Schmidt, Effects of diversity on performance in financial service teams: The joint impact of age-, tenure- and gender diversity (submitted).

[22]H. Tajfel and J.C. Turner, The social identity theory of intergroup behaviour, in: S. Austin and W. G. Austin, eds., Psychology of Intergroup Relations, Nelson, Chicago, 1986, pp. 7-24.

[23] S.M.B. Thatcher and P.C. Patel, Demographic faultlines: A meta-analysis of the literature, Journal of Applied Psychology (2011), 1-21.

[24] D. van Knippenberg, C.K.W. de Dreu, and A.C. Homan, Work group diversity and group performance: An integrative model and research agenda, Journal of Applied Psychology 89 (2004), 1008-1022.

[25]D. van Knippenberg and M.C. Schippers, Work group diversity, Annual Review of Psychology 58 (2007), 515-541.

[26]P. Warr, Age, work and mental health, in: K.W. Schaie and C. Schooler, eds., The impact of work on older adults, Springer, New York, 1997, pp. 252-296.

[27] J. Wegge, Heterogenität und Homogenität in Gruppen als Chance und Risiko für die Gruppeneffektivität [Heterogeneity and homogeneity in groups as chances and risks for group effectivity], in: S. Stumpf and A. Thomas, eds., Teamarbeit und Teamentwicklung, Hogrefe, Göttingen, 2003, pp. 119-141.

[28] J. Wegge, F. Jungmann, K.-H. Schmidt, and S. Liebermann, Das Miteinander der Generationen am Arbeitsplatz [The cooperation of generations at work], iga Report 21 (2011), 64-97.

[29] J. Wegge, C. Roth, B. Neubach, and K.-H. Schmidt, R. Kanfer, Age and gender diversity as determinants of performance and health. The role of task complexity and group size, Journal of Applied Psychology 93 (2008), 1301-1313.

[30] J. Wegge and M. Shemla, Diversity-Management, in: W. Sarges, eds., Management-Diagnostik (4. Aufl.), Hogrefe, Göttingen, in press.

[31]J. Wegge and K.-H. Schmidt, The impact of age diversity in teams on group performance, innovation and health, in: A.-S. Antoniou, C.L. Cooper, G. P. Chrousus, C.D. Spielberger, and M.W. Eysenck, eds., Handbook of managerial behavior and occupational health, Elgar, Northhamptom, 2009, pp. 79-94.

[32] J. Wegge, K.-H. Schmidt, S. Liebermann, and D. van Knippenberg, Jung und alt in einem Team? Altersgemischte Teamarbeit erfordert Wertschätzung von Altersdiversität [Young and old in one team? Age diverse teamwork requires appreciation of age diversity], in: P. Gellèri and C. Winter, eds., Potenziale der Personalpsychologe. Einfluss personaldiagnostischer Maßnahmen auf den Berufs- und Unternehmenserfolg, Hogrefe, Göttingen, 2011, pp. 35-46.

[33] K.Y. Williams and C.A. O'Reilly, Demography and diversity in organizations: A review of 40 years of research, Research in Organizational Behavior 20 (1998), 77-140.

[34]D. Zerssen, Die Beschwerden-Liste [The health disorders list], Beltz, Weinheim, 1976. 